\title{
Understanding the Impact of TVIs on Technology Use and Selection by Children with Visual Impairments
}

\author{
Catherine M. Baker ${ }^{\dagger}$ \\ Journalism, Media, \& Computing \\ Creighton University \\ Omaha, NE USA \\ catherinebaker@creighton.edu
}

\author{
Lauren R. Milne ${ }^{\dagger}$ \\ Mathematics, Statistics, \& \\ Computer Science \\ Macalester College \\ St. Paul, MN, USA \\ lmilne@macalester.edu
}

\author{
Richard E. Ladner \\ Computer Science \& Engineering \\ University of Washington \\ Seattle, WA, USA \\ ladner@cs.washington.edu
}

\begin{abstract}
The use of technology in educational settings is extremely common. For many visually impaired children, educational settings are the first place they are exposed to the assistive technology that they will need to access mainstream computing devices. Current laws provide support for students to receive training from Teachers of the Visually Impaired (TVIs) on these assistive devices. Therefore, TVIs play an important role in the selection and training of technology. Through our interviews with TVIs, we discovered the factors that impact which technologies they select, how they attempt to mitigate the stigma associated with certain technologies, and the challenges that students face in learning assistive technologies. Through this research, we identified three needs that future research on assistive technology should address: (1) increasing focus on built-in accessibility features, (2) providing support for independent learning and exploration, and (3) creating technologies that can support users with progressive vision loss.
\end{abstract}

\section{CCS CONCEPTS}

- Human-centered computing • Accessibility • Empirical studies in accessibility

\section{KEYWORDS}

assistive technology; teachers of the visually impaired; children with visual impairments

\footnotetext{
${ }^{\dagger}$ The authors contributed equally to this work

Permission to make digital or hard copies of all or part of this work for personal or classroom use is granted without fee provided that copies are not made or distributed for profit or commercial advantage and that copies bear this notice and the full citation on the first page. Copyrights for components of this work owned by others than the author(s) must be honored. Abstracting with credit is permitted. To copy otherwise, or republish, to post on servers or to redistribute to lists, requires prior specific permission and/or a fee. Request permissions from Permissions@acm.org.

CHI 2019, May 4-9, 2019, Glasgow, Scotland UK

(c) 2019 Copyright is held by the owner/author(s). Publication rights licensed to ACM.

ACM ISBN 978-1-4503-5970-2/19/05...\$15.00

https://doi.org/10.1145/3290605.3300654
}

ACM Reference format:

Catherine M. Baker, Lauren R. Milne, \& Richard E. Ladner.. 2019. Understanding the Impact of TVIs on Technology Use and Selection by Children with Visual Impairments. In 2019 CHI Conference on Human Factors in Computing Systems Proceedings (CHI 2019), May 4-9, 2019, Glasgow, Scotland, UK. ACM, New York, NY, USA. 13 pages. https://doi.org/10.1145/3290605.3300654

\section{INTRODUCTION}

Prior work has shown that individuals with disabilities can feel self-conscious about using assistive technologies or accessibility features on mainstream devices [21,22]. They can also feel frustrated by the usability of these devices [24], which can lead them to abandon these devices [19]. Recent work suggests that the social issues can have an even bigger impact on teenagers and tweens than adults because of the added social pressures in middle and high school [4,22]. However, there is little work looking at how the social and usability challenges impact the use of technology by teenagers and children with visual impairments in educational settings.

Many individuals with visual impairments have their first introduction to assistive technology in school. Because of laws like IDEA [10], they can receive support and training on this technology from Teachers of the Visually Impaired (TVIs) while in primary and secondary school to ensure that they are able to access educational curriculum. However, to the best of our knowledge, the last look at how children with visual impairments are using technology in educational settings was a set of surveys completed in 2005 and 2008 [11,26]. These surveys looked broadly at how students receiving special education services performed at school and documented the services they received. However, although the surveys asked if the students used assistive technology, they did not include very detailed information about what types of technology the students used or how often.

We sought to gain a better understanding of how children with visual impairments are using both mainstream and assistive technologies in educational settings through semi-structured interviews with six TVIs. 
We interviewed teachers who worked with students ages 5-21 from both residential and mainstream schools. We sought to answer the following questions:

RQ1: What factors do TVIs take into consideration when selecting and teaching technology for the student to use?

RQ2: What factors do TVIs think affect the students' use or non-use of technology?

We were interested in exploring these questions from the perspective of the TVIs, as they work with the children to select and train them on technologies they will use and may play a role in mitigating factors that may cause a student' abandonment of technology. Based on our interviews, we summary our results in three main areas. The first is the technology that the children with visual impairments are using and the factors that go into selection. The second is the association between technology and disability identity and how students will resist technology that do not match the disability identify they want to portray or their internal disability identity. Finally, we discuss the challenges that can hinder a visually impaired child's ability to learn the technologies.

Based on these challenges, we discuss the limitations of current technologies and describe three areas of opportunities for design. This can be used to inform future work on designing technologies for children with visual impairments and assistive technology more generally.

\section{RELATED WORK}

\subsection{Assistive Technology Use by Adults with Visual Impairments}

In this section we describe the prior research into the assistive technology use by individuals with visual impairments. The research in this section primarily focuses on adults. As the technology choice of adults is likely impacted by the technology they learn as children, our research will provide insights into why certain technologies are selected.

Prior research has looked at the use of assistive technology by adults with visual impairments in specific environments. Branham and Kane looked at how adults who are blind manage their assistive technology needs at home [6] and work [7]. Both papers highlight many of the factors that affect the use and non-use of technology. These include: that companies often dictate the technology, the desire to minimize the need for assistance from peers and the potentially contradicting needs of sighted and blind peers. In many of these cases, the adults have to find their own accommodations; however, children in an educational setting have additional supports, which may mean they face different challenges.

Others focused on the experiences of visually impaired users with specific technologies. Kane et al. [12] focused on the selection and use of mobile devices by individuals with visual impairments and mobility impairments. Brady et al. [5] focused on the specific types of visual questions that are asked on a social Q\&A app to better understand the needs of people with visual impairments. Zolyomi et al. [25] interviewed the early adopters of eSight, a new technology for people with low vision. They looked at the factors that affect both the adoption and the continued use of the technology. This prior research into specific technologies gives us insights into the selection and use of these specific devices. However, it focuses on device-level challenges and issues. In this paper, we focus on higherlevel problems when these types of technologies are used in classrooms as opposed to device-specific problems.

Researchers have also explored technology use more generally. WebAIM routinely surveys users with various disabilities, including screen reader users [27] and people with low vision [28]. The surveys provide information on which technologies are most commonly used and some of the issues they encounter, but does not detail the factors that affect technology selection. Szpiro et al. interviewed adults with low vision about their technology use. They discussed the technology used and highlight many of the challenges with technology, including difficulty with gestures, confusion, and inefficiency. Many of the users did not have, but wished for, training on the devices they used. As children who have a visual impairment are able to receive training from a TVI, the issues that adults without training face may be different than the children's issues and our work hopes to elucidate the challenges that may be specific to children in educational setting.

When looking at assistive technology use, factors beyond their access needs often come into play. Shinohara et al. [21] recommend that social acceptability should be considered when designing assistive technology, and, whenever possible, assistive technology should be directly integrated into mainstream devices. Factors of social acceptability are likely to be even more important when designing for teenagers and middle-schoolers because of the added social pressures at those ages. Because of this, we explicitly asked the TVIs to discuss the factors related to social acceptability that they found affected the children's use of assistive technologies. 


\subsection{Technology Use by Children with Visual Impairments}

There is up-to-date information on how adults with visual impairments are using both assistive technology such as screen readers [27] and mainstream technology such as mobile devices [9]. There are also numerous studies looking at how (mainly sighted) children are using technology [14,20,29]. However, there is not much information on how children and teenagers with visual impairments are using technology.

The largest studies that look into how children with visual impairments use technology are part of two larger longitudinal studies that documented the experiences of students with disabilities in educational settings in the United States. The first was a 5-year study that followed students through elementary to high school and ended in 2005 [30] and the second was a 5-year study that followed children from preschool to elementary school and ended in 2008 [11]. These studies only reported basic information about whether children with visual impairments were using assistive technology in order to access the curriculum. Unfortunately, the survey results seem to indicate that students with visual impairments are underserved in terms of access to this technology. A detailed analysis of the survey data by Kelly et al. [13] found that "between $59 \%$ and $71 \%$ of the students with visual impairments who were most inclined to benefit from assistive technology did not have the opportunity to use assistive technology" and that students who received non-itinerant instruction from a TVI were much more likely to use assistive technology than those who received itinerant instruction. The lack of current information on how children with visual impairments are learning and using technology is a hole in the literature that we seek to remedy with these interviews.

Unfortunately, increased reliance on TVIs and on assistive technology can come with a downside. In interviews with educators in the UK, Metatla [18] found children with visual impairments in mainstream classrooms were often isolated from their sighted peers by both the technology they used and because of the near constant presence of an adult in the form of a teaching assistant. In co-design work based on these interviews, Metatla and Cullen [17] emphasized that the current technology the students were using was designed to support accessibility over inclusivity and recommended that future technology should have more of an emphasis on inclusion and independence.

There have been smaller scale studies that look in particular at how teenagers with visual impairments are using social media. Libera et al. found that the teenagers with visual impairments preferred social media applications that rely less on photos [15]. Bennett et al. explored this topic in depth: looking at how teenagers with visual impairments share photos on social media [4]. They found that the teenagers with visual impairments used or wanted to use of photo-heavy social media platforms, though they may need special strategies to access the photos.

There has been work exploring how assistive technology can be seen as stigmatizing for people with disabilities [21,22]. In interviews with teenagers with visual impairments in Norway, researchers found that teenagers with low-vision tended to reject using assistive technologies whenever possible as they saw these technologies as stigmatizing and symbolic of dependency, but were very open toward using more "mainstream" technologies [22]. They also found that teenagers who were blind tended to be more open to using assistive technology; likely because they would be unable to access most computing technology without it.

\section{METHOD}

To answer the research questions, we conducted semistructured interviews with TVIs to determine how children were using and being trained to use technology at school. We then transcribed and analyzed the interviews to identify relevant themes.

\subsection{Participants}

We recruited six teachers (two male, four female) from our contacts within the community, word of mouth and snowball sampling. We drew from the population of approximately 90 TVIs in Washington State [16]. Approximately $84 \%$ of students with visual impairments are educated in their local schools [1]; There are generally very few students with visual impairments in a single school, therefore, the majority of these teachers work itinerantly, traveling between mainstream public schools in a single district to work with students. According to a 2007 report, 59\% of the TVIs in Washington State work in the state's school districts as either itinerant or resource room teachers, $23 \%$ work with students at the state residential school for the blind and $8 \%$ are based at the residential school but do outreach and provide support across the entire state. The remaining TVIs are contract workers or work for the Department of Blind Services or Washington Sensory Disability Services [3]. We interviewed teachers from each of these populations: three itinerant teachers, two teachers who work primarily with students at a residential school for the blind, and one who 
is based at the residential school, but travels to provide assistive technology support across the state. Of the itinerant teachers, two worked in a large school district where there were multiple TVIs and one worked in a small school district ( $<10,000$ students), in which she was the only TVI.

We started recruitment through our existing contacts in the community. We contacted three teachers via email asking if they were interested in doing the interview. During the course of these initial interviews, the teachers recommended that that we reach out to the remaining three teachers as they were very knowledgeable about assistive technology. This means the TVIs in our interviews likely had more expertise on assistive technology than the general population of TVIs. All of the teachers that were contacted agreed to be interviewed. Teachers were paid $\$ 35 /$ hour for completing the study.

\subsection{Procedure}

We conducted semi-structured interviews that ranged in length from 20 to 60 minutes. We audio-recorded the interviews for data collection purposes. Participants were asked broadly about their work, what kinds of technology they use with students, how they chose to introduce these technologies and what types of problems they encounter pertaining to the technologies. We formulated the interview questions based on our existing knowledge and prior work on (1) how both adults and children with visual impairments use technology [11,24,27,30], (2) how students with visual impairments are taught to use technology [2,8] and (3) barriers that adults and children with visual impairments encounter when using technology $[4,21,22,24]$. We narrowed down the questions using our overarching research questions to ensure the interviews were not longer than an hour.

\subsection{Analysis}

The audio-recorded interviews were professionally transcribed. We used grounded theory to analyze the interviews. During data collection and analysis of the first two of interviews, we brainstormed and developed codes. Then the first two researchers independently coded up the rest of the interviews, meeting to discuss any disagreements or new codes. All interviews were double coded and when we disagreed on a code, we discussed the issue until we reached agreement. We continued data collection and analysis until we reached saturation: that is, no new strategies for introducing technology, technology use patterns or challenges emerged. After coding all the interviews, we developed themes using axial coding [23].

\section{FINDINGS}

\subsection{Technology Use and Selection}

The TVIs described a number of technologies that they used with their students, including both mainstream tools and accessibility features. We summarize the different types of technology used and the reasons for selecting them in the following section.

4.1.1 Technologies Used. We found that the TVIs train their students on a wide variety of assistive technologies, which are listed in Table 1. In terms of hardware, students with visual impairments use iPads, sometimes connected to a Bluetooth keyboard, as well as laptop or desktop computers. Students who are blind might use a Braille display connected to their computer or even a stand-alone computer with a Braille display instead of a screen (called a Braille Notetaker). However, because these devices are expensive, they are limited to students with high academic ability. P1 noted that they have to "triage" in determining how to buy AT for her students. She said that "you make sure that your highest need person...by highest need (I mean) academic rigor (combined) with cognitive ability. that person he gets everything he can." Similarly, P2 noted that even at a residential school for the blind, cost is a consideration in purchasing the specialized Braille Notetakers and that they generally only give them to seniors who are headed to college.

Students with low-vision also use video magnifiers. Multiple teachers (P1, P3 and P4) note that these are one of the more challenging pieces of technology to get students to use, mostly for social reasons:

The other assistive technology... they're always going to use the Braille...but people will get a low-vision magnifier and because of social reasons, for whatever reasons, they won't use the video magnifiers. - P3

In terms of software, the blind students learn whichever screen reader matches the type of device they are using: ChromeVox for Chromebooks, VoiceOver for Apple products, and JAWS or NVDA for Windows PCs (P4 noted that they had tried to use the less popular Window-Eyes and Narrator screen readers in the past but were no longer using them). Oftentimes the screen reader dictates the device that the TVI teaches the students: P2, P5 and P6 all stated that the superior accessibility features on the iPad mean that they use that tablet with their students instead of an Android tablet. P2 explained that "the school just teaches VoiceOver because it's much better." 
The low-vision students use a variety of magnification software on their tablets and computers. These include (1) the built-in "mainstream" features (e.g. pinch-to-zoom on a tablet, ctrl+ in a web-browser), (2) the built-in "accessibility" features (e.g. the accessibility magnifiers which zoom in on a portion of the screen or the color contrast) or (3) additional magnification software such as ZoomText or Fusion (which combines the magnification of ZoomText with the JAWS screen reader). Three of the TVIs (P1, P5 and P6) noted that the built-in "accessibility" features for low-vision are generally poor and their students prefer to use the built-in "mainstream" features or the additional magnification software. P6 says:

We used to teach the magnification that's built in like Windows and stuff. It's pretty awful. To be honest, it's really awful.... you set it on a little window of magnification that zooms in on part of the screen and it's hard to keep track of where your mouse is, you can make the mouse a little bigger but not that big.

Finally, many of the TVIs (P1, P2, P4, P6) expressed that many of their students prefer using more mainstream devices. In the words of P2, "If we could teach them normal technology that's better. Voiceover is just part of an iPad, Siri is just part of an iPad, right, there's no special program that was downloaded." This may be due in part to a desire on the part of the students to fit in.

All six of the teachers mentioned that they used mobile touchscreen devices (iPads in particular) with their students for multiple reasons. One of the main benefits is that the built-in accessibility of iPads is extremely good. When asked if the use of iPads was particular to the students with visual impairments or was reflective of the technology the sighted children were using, P5 replied:

No, it's very particular to students with visual impairment, it's a very useful technology, I mean if you have a low-vision student they can take pictures of things on the board and enlarge it. ... and there's software now that you can take pictures of a math page and enlarge it and actually work on it in an app in the iPad.

Much like P5 noted, P1 has noted that students would repurpose the iPad, a mainstream device, to take the place of assistive technology, such as physical magnifiers. Students will also repurpose mainstream technology to avoid learning some of the skills they need to access their computing device. For instance, P2 found that many of her students would avoid learning to use the keyboard by continually using Siri for dictation.

Additionally, the iPad was often used an an introductory technology due to its simpler interface and the fact that it is common for younger children to have been exposed to mobile devices early. P5 said:

These days even at the preschool level many of them have had exposure to touchscreens: like tablets, iPads, their parents' phone. ... I see every single student that comes in and most of them do have early exposure to those technologies.

P6 stated that they often start young children with

Table 1. Description of the assistive technologies taught by the TVIs

\begin{tabular}{|l|l|l|}
\hline \multicolumn{1}{|c|}{ Technology } & \multicolumn{1}{|c|}{ Description } & \multicolumn{1}{c|}{ Examples } \\
\hline $\begin{array}{l}\text { Refreshable } \\
\text { Braille Display }\end{array}$ & $\begin{array}{l}\text { Display for screen reader output that uses small } \\
\text { metal pins that pop up to create Braille } \\
\text { characters. Often integrated with a keyboard. }\end{array}$ & Brailliant Series by Humanware \\
\hline Braille Notetaker & $\begin{array}{l}\text { Stand-alone computer (with similar computing } \\
\text { power to a smartphone) with Braille display. }\end{array}$ & Braille Polaris, BrailleNote Touch \\
\hline $\begin{array}{l}\text { Video Magnifier/ } \\
\text { CCTV }\end{array}$ & $\begin{array}{l}\text { Video camera that projects a magnified image } \\
\text { onto a display. }\end{array}$ & $\begin{array}{l}\text { Various stand-mounted and handheld cameras } \\
\text { work with screen or head-mounted displays }\end{array}$ \\
\hline Screen Reader & $\begin{array}{l}\text { Software that reads aloud elements on the screen } \\
\text { and allows user to navigate and select elements. }\end{array}$ & $\begin{array}{l}\text { JAWS, ChromeVox, } \\
\text { TalkBack }\end{array}$ \\
\hline $\begin{array}{l}\text { Magnification } \\
\text { Tools }\end{array}$ & $\begin{array}{l}\text { Features that can be used to adjust text sizing, } \\
\text { text color or zooming. Magnification windows } \\
\text { that can be used like a magnifying glass. }\end{array}$ & $\begin{array}{l}\text { Mainstream (Pinch-to-zoom, } \\
\text { accessibility features (Windows Magnifier and } \\
\text { MacOS Zoom) }\end{array}$ \\
\hline $\begin{array}{l}\text { Magnification } \\
\text { Software with } \\
\text { Screen Reader }\end{array}$ & $\begin{array}{l}\text { Stand-alone software that combines } \\
\text { magnification tools with some screen reader } \\
\text { features. }\end{array}$ & $\begin{array}{l}\text { ZoomText (magnification features with limited } \\
\text { screen reader) and Fusion (combination of } \\
\text { ZoomText and JAWS) }\end{array}$ \\
\hline
\end{tabular}


iPads and then transition them to computers when they learn to type. P2 noted one reason it can be easier for blind students to learn to use an iPad is because they have do not have to learn the hundreds of key commands that they would have to on a laptop because the iPad is gesture-based.

One of the challenges both the blind and their lowvision students encounter in learning to use the touchscreens is how to explore the screen. Other problems students encountered included difficulty performing the screen reader gestures (e.g. double tap to select or twist to engage the rotor) and usability problems (e.g. features that move the focus do not work well with screen readers).

\subsubsection{Matching Technology of their Peers. The teachers} teach their students a similar set of technologies regardless of whether they are at a residential school or a mainstream school; however, they do try to match the technology of the school district when possible. In P1's school district, this means the students use Chromebooks at the elementary and middle school and then iPads for high school. However, she noted that because of accessibility problems with integrating Braille displays and ChromeVox (the screen reader for Chromebooks) her blind elementary school-aged students are using iPads instead. At the residential school for the blind, P2 and P4 teach at, the middle schoolers receive iPads and Bluetooth keyboards and the high schoolers receive PC laptops. However, P2 notes that they tweak what technology is given to students to match their personal needs.

Two of the TVIs (P1, P6) mentioned that matching the technology of the other students in the class makes it easier for students with visual impairments to collaborate with their peers. P1 described a situation in which a blind child could collaborate with a sighted peer or teacher while using an iPad or a computer:

Everything is right there on the screen and so a sighted person just reads the screen and the blind person reads the Braille display.... It's really nice for teachers too because they can see the kids work as they work.

P6 echoed the idea that having students using the same technology makes it easier for them to collaborate and noted that they usually will "train" the sighted student, so they have some familiarity with the assistive technology.

\subsubsection{Other Factors for Selecting Technology. In} determining which technology a student should use, P4, who determines the technology needs of students at a residential school, follows the SET framework: "you consider the student, the environment, the task and then finally the tool that you're going to use.” For example:

Let's say we have a student who will, let's start with a Braille student first, they're still learning the Braille code, then a device like a Braille Note would be extremely helpful for them because they would be practicing the reading and writing of Braille all throughout the day.... So it would make sense for them to be on a device like that versus having them learn keyboarding and a laptop. -P4

She elaborated on how the environment affects the choice of tool, and that they might chose different tools to support a student in a school environment versus a work environment or for learning orientation and mobility.

Cost was cited as a concern by four of the TVIs, although the concern level varied based on what type of school they taught at. P2 explained that cost was less of an issue at the residential school: "if we can hand it to them it's no longer a financial barrier...if...they learn to use it and they can prove they need it for future times, blind services will buy it for them." However, P2 noted that she advocates for her students to learn a laptop and refreshable Braille display instead of the all-in-one notetakers (e.g. BrailleNote) because the notetakers are expensive and challenging to replace, even if they originally receive one for free. In terms of software, both P1 and P6 noted that they preferred teaching their students to use the free or built-in screen readers (e.g. NVDA and VoiceOver) to JAWS because of the expense.

The TVIs mentioned a number of other factors that they consider when selecting technology: the student's academic ability, vision and personal preferences. Students who are blind generally require more technology and training than students with low-vision. Students with higher academic ability are under more pressure to keep up with the general education curriculum, and so there is more pressure to ensure they have access to all the best assistive technology. The TVIs also keep in mind personal preferences when selecting technology. These range from an aversion to synthesized speech to a desire to use only familiar technology. P5 noted the importance of considering the student when selecting technology:

I really try to meet people where they're at, you know, and like I try to figure out, like ... what is doable...because she spent the last three years learning VoiceOver on the iPad and she doesn't ever use it, so I'm not going to do that with her. 
4.1.4 Technology Skills and Experience. The TVIs in our interviews often thought that their students do not have as much exposure to technology as their sighted peers. When discussing her students experience with technology, P2 said:

Not as much technology as your average middle schooler. Most of our average middle schoolers out there have a cell phone, have an iPad, ... I would say $50 \%$ of our kids don't... so learning how to navigate any of that is taught as like a new skill in middle school.

Three of the TVIs (P2, P4, P5) highlighted learning typing as one skill that is both especially important and challenging to teach students with visual impairments. P2 said "This year we had a big group of 6th graders and none of them knew how to type. You could give them a number pad and they can't dial home." She further noted, "they have been really resistant to learning to type they just want to dictate everything or ask Siri everything." P5 said that it's very important for her students to learn to type as often students with low-vision have bad handwriting, so she starts teaching them to type as early as possible. Both P2 and P4 noted that traditional typing programs are not accessible, and while accessible versions exist, they tend to be less engaging and fun.

\subsection{Technology Reinforces Disability Identity}

In our interviews, a common theme that arose is the relationship between the technology the students are using and their disability identity. While for some students this is a positive relationship (I can do something others cannot, and I am proud of it), for many of the students the relationship is negative. These associations between the technology and disability identity can be both external and internal. For some students, the external perceptions are the largest factor in their acceptance or rejection of technology. They do not want other students to perceive them as being different, having a disability. For other students, the internal perceptions are the largest factor in acceptance or rejection of the technology. These students do not perceive themselves as having a disability and therefore do not need the assistive technology.

4.2.1 External Disability Identity. For many students, the resistance to using assistive technology comes from managing other students' perceptions of their disability. They do not want other students to notice their disability. P6 noted, "I mean a lot of kids who are afraid to stick out especially like in middle school and stuff, you know, and they start not wanting to use their devices and everything because they don't want to stick out with different everything." $\mathrm{P} 1$ thought that this is particularly true for students with low-vision: "Especially kids with quite high acuities, relatively high vision acuity and their vision is stable, nothing is getting worse, those kids for sure they like to pass."

Because these students do not want technology that will draw attention to their disability, they will resist using technology that is different from other students. When given the choice for magnification, many students will select the built-in technology that is used by both visually impaired and sighted students over technology that would be specific to someone with a visual impairment. For the iPad, this means that students are less resistant to pinch-to-zoom over using the magnifier box:

Oh, everybody's doing it [using pinch to zoom] all the time. And that and you know they can see their sighted peers doing it too and then it's just no big deal. Whereas if you've got that magnified box, you're going to stand out. Partially sighted kids tend to be quite guarded about their peers knowing. -P1

For technologies that do not have an unobtrusive option for the student to use, they may choose to just go without access. For instance, there is a technology that allows a teacher's screen to be transmitted to the student's iPad so that they can see it more easily. However, P1 often found that the students would not use the technology: "They would rather not see and just imagine." In order for this software to work, the teacher must explicitly invoke it. If the teacher forgets to turn it on, then the student has to ask for it to be turned on, thereby drawing additional attention to their disability, which may be why they choose to go without.

The resistance to technology is not just limited to assistive technology. Mainstream technology can still make students stand out to their peers if they are the only one using it:

I mean I've had students who don't like to use iPads because they are the only one that has an iPad, you know. I think if all the kids are using something then they just have an accessibility feature going on, they don't mind that as much. But, as soon as it's something that only they're using, a lot of times they don't like that. - P6

4.2.2 Internal Disability Identity. Beyond managing the disability identity that they present to their peers, some students are resistant to technology that does not match their internal disability identity. Many technologies are associated by the students with specific levels of vision 
impairment. P4 stated: "they also know that the people who use JAWS don't have vision or very usable vision and they don't want to perceive themselves that way." When students do not believe that their visual condition matches the technology they are being taught, they can be resistant to learning it.

For students that have a degenerative condition, this can be particularly important as the technologies they are learning will likely not match their current level of vision. Many TVIs will begin teaching the students the technology the students will need as their vision decreases before they reach the state that they need it. However, this can be very hard on the student:

It's just the emotional, mental, I mean they're young and it's hard to grasp that their vision will be getting worse and there's the denial, there's you know, all that kind of stuff that goes with it. If you say JAWS, the students here know, they know who the JAWS users are and right now they know how different they are from the JAWS users in terms of their vision. -P4

If they are in denial about their vision worsening, then they will not be open to learning the technologies that are not currently needed but will be needed in the future and take time to learn.

The association of technology with disability identity is not always negative. There are some students who are proud of the skills they have gained from the technology they use. They see that they have unique skills that allow them to do things that other students cannot do:

It's interesting and those are usually my older students who have kind of come to terms with it, they're finding some pride in their identity as, 'Okay this is part of who I am and it's not a bad thing, it makes me unique, I can do something most other people can't, yep, I can read in the dark.' - P2

4.2.3 TVI Framing of Technology. Due to the issues related to the associations between technology and disability identity discussed above, we found that the TVIs will often frame their introduction of the technology or skills to combat some of the negative associations.

For instance, when teaching a student who uses magnification software the keyboard commands for actions such as closing an application, one TVI mentioned trying to link the less common keyboard commands with those that are commonly used by many people (e.g. the copy and paste keyboard command):
So, I'll say to the kids hey you know, a lot of the fully sighted kids would just love to know these commands and they'll wonder you know, if you start using these really fluently, they're going to think you are super cool. -P1

Since some students have been resistant to learning these skills, potentially due to their impressions that they are only used by someone who has a disability, the TVI has framed the skills as mainstream technology skills, instead of assistive technology specific skills.

Other TVIs have run into issues with students who have degenerative vision condition that will get worse. They associate certain assistive technologies with different levels of vision. This can be an issue when the TVI is trying to introduce the technology that they will need when their vision worsens. Many technologies are associated with specific levels of vision, so some students are resistant to technology which doesn't match their current vision level, even if they will need it in the future. As students do have these associations between certain technologies and vision levels, some TVIs will avoid mentioning JAWS, while still ensuring they learn the skills they will need to use it in the future:

I haven't talked to them about ZoomText, haven't talked to them about JAWS, have just gone directly to Fusion, because right now it's the magnification they need. So, voice is there too, and they're learning all the JAWS stuff without even knowing that that's what they're kind of learning... which is kind of a good thing because they oftentimes have a hard time with this transition. -P4

By using a technology like Fusion, which combines ZoomText and JAWS into a single product, the TVIs are avoiding the resistance to JAWS. Fusion blends the magnification software and the screen reader, which means it does not have the same associations with only being needed by students with a certain level of vision like JAWS does.

\subsection{Challenges in Learning Assistive Technology}

Another theme that came up repeatedly in our interviews was that the assistive technology was challenging to learn and that coming up with motivating examples was an important part of the teachers' jobs. We found that the technology was hard to learn both because it introduced extra layers to learn on top of whatever content the student was trying to access and because a lot of the technology was buggy or not user-friendly. 
4.3.1 Learning Extra Layers. Both P1 and P2 repeatedly emphasized that their students had to take additional steps and learn additional skills in order to access the same materials as sighted children. In describing one student, P1 pointed out:

He had to learn how to keyboard, he had to learn how to listen, and he had to learn how to separate what I call everybody commands, you know standard keyboard commands like command-q for quit, command-w for closing a window...so separating the everybody commands from VoiceOver commands.

She noted that her blind students have to learn how to split attention between their screen readers and their group or teacher. P2 noted that it was hard to learn many academic skills and even harder to learn them in conjunction with assistive technology:

I use MathType that translates into LaTeX that will then emboss ... with so much less work on my end, but it's teaching them yet another code to be able to do their math.... It's just one more layer to learn before you can learn, it's just one more thing that slows our kids down, just one more step.

Any of her students who use Braille would also have to learn a typesetting language (such as LaTeX) if they wanted to write math equations that a non-Braille reader could understand. While this could be a useful skill to have, it also can be a barrier when they are just trying to learn math.

\subsubsection{Usability Problems and Bugs. All of the TVIs}

mentioned encountering usability problems and bugs with the assistive technology. These challenges included curricular materials that could not be accessed with the assistive technology: web-based programs that were missing alternative text or labels, or testing materials that did not allow for magnification.

Some of the problems were bugs or usability issues with the assistive technology itself. P1 mentioned usability problems with the combination of Chromebooks and ChromeVox:

Last year district tech, a nice person, announced that she was going to help me achieve accessibility [on Chromebooks] and I said, "I would love your support" and we worked for three hours and just couldn't get in. It's just we'd get you know $85 \%$ there and then roadblock. Horrible.
P1 developed strategies to shield her students from some of the worst of the usability problems. When describing why she had not obtained a BrailleNote Touch for one of her students, she said:

We know it's going to be buggy, so give it two years and then cause I'm not going to take a fourth grader and make him alpha test. It'd be different if he was an adult, but no, I'm not going to do that to him.... I just want him to have confidence.

She noted that the usability problems were particularly problematic for children:

With a little fourth grader, entering fourth grade, you can imagine, I just want him to have confidence.... [When] they can't navigate, it's depressing for them, they can't count on it. It's hard for us as teachers too to say, 'Hey this is going to work and then it doesn't.'

4.3.3 Little Support for Independent Exploration. In part because of the usability and social issues, many of the teachers thought that the assistive technologies do not support independent exploration very well and are not easy to learn without additional support. When asked if the students were likely to use the technology on their own, P5 replied, 'It's not going to happen because it's just, yeah, I don't see it. I just think about all my students, like my Gen. Ed. students..., It's just not going to happen, they don't do it." P4 thought that a recent policy change at her school in which students were given iPads before receiving any formal training meant that they often learned "bad habits" or shortcuts which meant they were more resistant or had trouble learning the more efficient accessibility features:

They're not perhaps learning the most efficient and effective ways to do things...Particularly for the iPad with Siri, they just rely on Siri to do most things...Using the on-screen keyboard instead of the Bluetooth keyboard, which is impacting their typing skills because they're most often using just their one hand and one finger to find the different keys ...So that's definitely the downside to just having the students have it and they learn on their own and explore on their own.

4.3.4 Technology Support. One of the factors that can impact a student's success in learning different technologies, is the level of support they receive. P5 notes that if the student doesn't have support in learning the technologies, "it's just not going to happen." This support 
comes primarily from the TVIs but can also come from the students' other teachers or their parents.

The primary support comes from the TVIs, who may have to learn the technology independently. P2 said about learning AT:

It's not something you learn in a TVI program, ... you don't really get like a TVI degree in AT, it's not a thing.... It's a little splattering but it's the school you went to, did they have things for you to play with? Did they actually teach you how to use it or did they just say, 'Hey these are things that are available'? It depends on where you went to college how much AT training you got.

Many of the TVIs we talked to were constantly working to stay up-to-date on the technology. Many manufacturers are willing to come train people on the technology as they hope to sell it, but most of the TVIs learn about the technology independently or from colleagues. P5 stated:

We are a department that's very passionate. People are constantly going to conferences, constantly reading things, constantly educating themselves, and so I think that's how a lot of things happen: where we have an issue and then someone reads a blog ... and will bring like a technology solution on to the team.

Gaining this knowledge can be challenging for the TVIs as they have many things they need to stay up to date on beyond just the technology. P2 noted one challenge:

Time to do everything because I'm also staying up on my standards. I'm doing new programming languages every time people turn around. So, there's that aspect and then there's Special Ed. law you have to stay up on and oh they're going to make us learn how to administer this kind of state test and oh there's so many aspects of staying up-to-date as a teacher.

While the TVIs are an excellent support for the students who are learning these technologies, they have limited time with the students. As such, students may turn to others for additional support. The students who were at a residential school, may choose to turn to their peers who may be using similar technologies. The students may also turn to their subject teachers who are not knowledgeable in the technology. Because of this, P5 said that he also tries to work with the students' other teachers:
I also try to communicate with teachers ... like this is a student's needs and that kind of helps sometimes getting them more support on-site, because I just go and see her 30 minutes a week...Really integrating technology into our students' lives can sometimes be really challenging especially when we don't have someone from our department on-site.

Many of these students' teachers are not familiar with the technology, so they cannot provide support a student needs without additional training themselves. P1 also noted that with changes in how her students were being provided technologies (changing from the student only receiving the technology for classroom use once they had mastered it to receiving it and learning along the way), she found that the classroom teachers were having to learn more about the assistive technology to be able to support their students.

This is also true for parents. Many times, the parents are not familiar with what technology is best for the students. The level of support that parents are able to provide can vary. When talking with a TVI who worked at a residential school for the blind (P4), she mentioned that the parent's involvement with the technology is minimal. Most often, the impact she sees from the parents is when they purchase technology for the students: "Unfortunately often times they just buy stuff for their child, and it's like, 'Oh I wouldn't have bought that, they might have bought an Android tablet when it might have been better to have bought an iPad."

The TVIs who work with students in mainstream schools have more involvement with the parents than those at the residential schools. P1 noted:

I will do trainings for the parents, like come in during the school day, and we'll have your kid sitting here and he'll show you what he knows, and you can ask questions and I'll help answer them. But again, for some of them it's a really steep learning curve. I do have expectations that they will support their child, but my expectations are not always met.

P5 said that while she tries to keep the families informed with what technology the student is learning and will often send technology home, she doesn't push the parents to work on specific skills with their children unless they specifically ask for that.

4.3.5 Lack of Motivation. P2 and P4 both mentioned that it could be hard to motivate students to learn some of the 
technical skills such as typing either because the students did not see how the skill would be useful for them or because there were not accessible and fun programs to teach it. However, the teachers explained that if the students were properly motivated they picked up the technology much more quickly, and a lot of this motivation comes from interacting with the same pieces of popular culture that their sighted peers are interacting with (e.g. Facebook or YouTube). P2 said,

So, we're just teaching some kids iPads. They're all obsessed with YouTube. Fabulous, go find a YouTube video that you think I want to watch and learn how to share it and email it to me. I had guys jumping into blue Jell-O, I had kittens, I had puppies, I had religious music, I had ...

\section{DESIGN OPPORTUNITIES}

The teenage and childhood years are a formative time, when individuals are learning who they are. It is important to design technology that both allows students to access to educational information, but also does not make them feel uncomfortable or bring emotional distress. Children with visual impairments often have to learn an extra layer of technology in order to interact with digital material. It is important to make this extra layer as easy to learn and use as possible, so they can focus on the educational content. Based on this, we discuss some of the limitations of current assistive technology and opportunities for design below.

\subsection{Design for Mainstream Technology}

In our interviews, we found that mainstream technologies were preferred over specialized assistive technologies. However, students were often not able to use the built-in assistive technology as it was not as functional as the specialized technologies. Therefore, we believe that it is important for companies to focus on improving the quality of the built-in technology features that can be used in place of specialized assistive technology.

There are many benefits that come from using more mainstream technologies. It is generally less expensive than specialized assistive technology. In agreement with previous work [21], we found that technology reinforces disability identity. Students who did not perceive their vision loss as commensurate with the technology they were using or wanted to hide their level of vision loss, would reject technologies that were associated with specific vision levels. Interestingly, we found that teachers would frame their introduction to the technology to combat some of the negative associations, including portraying skills as mainstream skills. Additionally, mainstream technology seemed to have less strong identity associations and perhaps less stigma. We believe that designing mainstream technology so that it can support individuals with a wide range of vision and making accessibility features on technology unobtrusive is especially important for children and teenagers, who might not yet be comfortable with their disability and are still forming their identity.

Finally, as mainstream technologies vary in their level of accessibility, students are often unable to use the technology that they would like. We found that TVIs preferred to match the technology of the other students in the class, but it often wasn't accessible. The students either have to deal with the bugs or switch to a different piece of technology. Additionally, parents would sometimes buy students technology that was not very usable as they were unaware of which technologies are best.

\subsection{Support Independent Exploration}

Through our interviews, it became apparent that assistive technologies are extremely difficult for students to learn. Students required a lot of support from teachers in order to successfully learn to use them. When the students did learn to use technologies such as the iPad on their own, they often learned inefficient ways of doing things. This corresponds with the findings in Szpiro et al. which found support for exploration was important for adults with visual impairments [24]. Because of all the issues with learning the new technologies, the TVIs felt that there was no way that students could succeed at learning these technologies on their own.

However, we found that there are educational ramifications for the limited explorations. As it is much harder to learn these technologies independently, students are already behind their peers in computer skills. This is particularly troubling as visually impaired students often must rely on technology for access to materials that sighted children can access regardless of technology skills. Therefore, it is important to provide scaffolding so that students can more easily learn technologies. Teachers also noted that it is hard to motivate students to learn some skills that they need in order to fully access the technology (e.g. typing), in part because there are few fun, accessible games to teach these skills. This indicates a need for technology that is learnable, as well as a need for fun and motivating ways to teach it.

Finally, through our interviews, it became clear that it was not just the visually impaired children who needed to be supported in their exploration of assistive technology. 
We found the need for the parents, subject teachers, and TVIs to have an understanding of the assistive technology in order to support the students learning of new technologies. In our discussions with the TVIs, people who are considered the experts on assistive technology, we found that they struggled to learn all the technologies and tips and tricks needed for students to successfully be able to use the assistive technology. When TVIs struggle with assistive technology, the likelihood of a parent or subject teacher being able to fill in that knowledge gap is very low. The TVIs would often teach parents and subject teachers enough to get by, but they would better be able to support students if they could easily learn these technologies themselves.

\subsection{Support Students with Progressive Vision Loss}

Teachers were enthusiastic about technology such as the Fusion software, which combines the JAWS screen reader with the ZoomText magnification software and can be used by individuals with low-vision as well as those who are blind. The teachers noted that this software was especially useful when working with students whose vision was worsening over time. Oftentimes, the students had a great deal of emotional stress associated with the vision loss. Having the students learn software that would work for them as their vision change is easier for them both emotionally (as they do not have to deal with the emotional ramifications of switching to a tool for a "blind" person) and cognitively (as they do not have to learn two separate pieces of technology). We believe that designing technologies to support individuals, and especially children, with progressive vision loss is an underresearched area that deserves more consideration.

\section{LIMITATIONS AND FUTURE WORK}

All of the teachers that we interviewed were based in one state and their experiences may not broadly represent teachers' experiences elsewhere. Our sample size for the interviews was small and because we were referred to and recruited teachers with special knowledge of assistive technology, their students likely have a higher dependence on technology. We learned about the technology experiences of these children indirectly through their teachers; an interesting next step would be to conduct interviews with the children themselves and observe how they are currently using technology. Additionally, as we specifically asked about barriers, our results have a high emphasis on those topics.

\section{CONCLUSION}

We conducted interviews with six TVIs to determine how children with visual impairments are using technology in educational settings and how teachers are training them on these technologies. We found that teachers are training their students on a wide variety of both mainstream (e.g. iPads and computers) and assistive technologies (e.g. magnifiers and screen readers). The teachers keep a number of factors in mind when choosing technology for their students: (1) the technology of the rest of the students, (2) what fits the individual student (based on visual ability, academic ability, vision and personal preference), and (3) what fits the tasks and environments the students need it for. The teachers report that many of their students had less exposure to technology than their sighted peers and often had challenges learning some of the skills needed to access these technologies.

We found that students face many challenges in trying to use the technologies. They have to learn an extra layer in order to access the same material as their sighted peers and often the technologies have usability problems and bugs. Based on these challenges, we discussed the limitations of current technologies and describe three areas of design opportunities: (1) designing for mainstream technologies, (2) increasing support for independent exploration of these technologies and (3) designing technology that supports students with progressive vision loss.

\section{ACKNOWLEDGMENTS}

This material is based upon work supported by the National Science Foundation under Grant No. 1539179 and the Henry Luce Foundation - Clare Boothe Luce Fund.

\section{REFERENCES}

[1] American Printing House for the Blind. APH - Distribution of Eligible Students Based on the Federal Quota Census of January 6, 2014. Retrieved from http://www.aph.org/federalquota/distribution-2015/

[2] Andrew Leibs. Learn Why iPad Is a Great Learning Tool for Visually Impaired Students. Lifewire. Retrieved July 18, 2018 from https://www.lifewire.com/ipad-ideal-tool-blind-visually-impaired198768\%0A

[3] Robert J. Beadles Jr. 2007. Identification of Statewide Services and Best Educational Practices for Washington State Students Who are Blind, Visually Impaired, and with Multiple Disabilities: A Study of the Washington State School for the Blind and Related Statewide Services. VI RehaB Consulting. Retrieved from http://www.iowaregents.edu/media/cms/wastatereportfinalreportju ne202007-pdf5A486AE7.pdf

[4] Cynthia L. Bennett, Jane E, Martez E. Mott, Edward Cutrell, and Meredith Ringel Morris. 2018. How teens with visual impairments take, edit, and share photos on social media. Conference on Human 
Factors in Computing Systems - Proceedings 2018-April: 1-12. https://doi.org/10.1145/3173574.3173650

[5] Erin Brady, Meredith Ringel Morris, Yu Zhong, Samuel White, and Jeffrey P. Bigham. 2013. Visual challenges in the everyday lives of blind people. In Proceedings of the SIGCHI Conference on Human Factors in Computing Systems - CHI '13, 2117.

https://doi.org/10.1145/2470654.2481291

[6] Stacy M. Branham and Shaun K. Kane. 2015. Collaborative Accessibility. In Proceedings of the 33rd Annual ACM Conference on Human Factors in Computing Systems - CHI '15, 2373-2382. https://doi.org/10.1145/2702123.2702511

[7] Stacy M. Branham and Shaun K. Kane. 2015. The Invisible Work of Accessibility: How Blind Employees Manage Accessibility in Mixed-Ability Workplaces. In Proceedings of the 17th International ACM SIGACCESS Conference on Computers \& Accessibility - ASSETS '15, 163-171. https://doi.org/10.1145/2700648.2809864

[8] Brian M. Celusnak. 2016. Teaching the iPhone with Voiceover Accessibility to People with Visual Impairments. Journal of Visual Impairment \& Blindness 110, 5: 369-372. Retrieved from https://files.eric.ed.gov/fulltext/EJ1114771.pdf

[9] Michael D. Crossland, Rui S. Silvia, and Antonio F. Macedo. 2014. Smartphone, tablet computer and e-reader use by people with vision impairment. Ophthalmic and Physiological Optics 34, 5: 552557. https://doi.org/10.1111/opo.12136

[10] IDEIA. 2004. Individuals with disabilities education improvement act.

[11] Washington Institute of Education Sciences (ED) DC. 2006. National Center for Special Education Research (NCSER) Projects and Programs: PEELS. Retrieved from https://ies.ed.gov/ncser/projects/peels/

[12] Shaun K. Kane, Chandrika Jayant, Jacob O. Wobbrock, and Richard E. Ladner. 2009. Freedom to roam. In Proceeding of the eleventh international ACM SIGACCESS conference on Computers and accessibility - ASSETS '09, 115. https://doi.org/10.1145/1639642.1639663

[13] Stacy M. Kelly. 2009. Use of Assistive Technology by Students with Visual Impairments: Findings from a National Survey. Fournal of Visual Impairment \& Blindness 103, 8: 470-480.

[14] Amanda Lenhart. 2015. Teens, social media and technology overview 2015: Smartphones facilitate shifts in communication landscape for teens. Pew Research Center, 1-47. https://doi.org/10.1016/j.chb.2015.08.026

[15] Bianca Della Líbera and Claudia Jurberg. 2017. Teenagers with visual impairment and new media: A world without barriers. British Journal of Visual Impairment 35, 3: 247-256. https://doi.org/10.1177/0264619617711732

[16] Craig Allan Meador. 2015. Meeting the needs of visually impaired students in Washington state: an exploratory study of the working conditions that affect teachers of the visually impaired. Washington State University. Retrieved from https://research.libraries.wsu.edu:8443/xmlui/bitstream/handle/2376 /5467/Meador_wsu_0251E_11319.pdf;sequence=1

[17] Oussama Metatla and Clare Cullen. 2018. Bursting the Assistance Bubble. In Proceedings of the 2018 CHI Conference on Human Factors in Computing Systems - CHI '18, 1-14. https://doi.org/10.1145/3173574.3173920
[18] Oussama Metatla and Oussama. 2017. Uncovering Challenges and Opportunities for Including Visually-Impaired and Blind Children in Mainstream Schools. In Proceedings of the 31st British Computer Society Human Computer Interaction Conference, 1-6. https://doi.org/10.14236/ewic/HCI2017.102

[19] Betsy Phillips and Hongxin Zhao. 1993. Predictors of assistive technology abandonment. Assistive technology: the official journal of RESNA 5, 1: 36-45. https://doi.org/10.1080/10400435.1993.10132205

[20] Vicky Rideout. 2015. The Common Sense Census: Media Use By Tweens and Teens. Common Sense Media, 1-104. https://doi.org/10.1017/CBO9781107415324.004

[21] Kristen Shinohara and Jacob O. Wobbrock. 2011. In the Shadow of Misperception: Assistive Technology Use and Social Interactions. In Proceedings of the 2011 Annual Conference on Human Factors in Computing Systems - CHI '11, 705. https://doi.org/10.1145/1978942.1979044

[22] Sylvia Söderström and Borgunn Ytterhus. 2010. The use and nonuse of assistive technologies from the world of information and communication technology by visually impaired young people: a walk on the tightrope of peer inclusion. Disability \& Society 25, 3: 303-315. https://doi.org/10.1080/09687591003701215

[23] Anselm Strauss and Juliet M. Corbin. 1990. Basics of qualitative research: Grounded theory procedures and techniques. Sage Publications, Inc, Thousand Oaks, CA, US

[24] Sarit Felicia Anais Szpiro, Shafeka Hashash, Yuhang Zhao, and Shiri Azenkot. 2016. How People with Low Vision Access Computing Devices. In Proceedings of the 18th International ACM SIGACCESS Conference on Computers and Accessibility - ASSETS '16 (ASSETS '16), 171-180. https://doi.org/10.1145/2982142.2982168

[25] Annuska Zolyomi, Anushree Shukla, and Jaime Snyder. 2017. Technology-Mediated Sight. In Proceedings of the 19th International ACM SIGACCESS Conference on Computers and Accessibility ASSETS '17, 220-229. https://doi.org/10.1145/3132525.3132552

[26] SEELS Info \& Reports: Behind the Label. Retrieved from https://www.seels.net/info_reports/visual_impairment.htm

[27] WebAIM: Screen Reader User Survey \#7 Results. Retrieved May 8, 2018 from https://webaim.org/projects/screenreadersurvey7/

[28] WebAIM: Survey of Users with Low Vision \#2 Results. Retrieved December 28, 2018 from https://webaim.org/projects/lowvisionsurvey2/

[29] The Common Sense Census: Media Use by Kids Age Zero to Eight 2017 | Common Sense Media. Retrieved February 17, 2018 from https://www.commonsensemedia.org/research/the-common-sensecensus-media-use-by-kids-age-zero-to-eight-2017

[30] Special Education Elementary Longitudinal Study (SEELS) | SRI International. Retrieved April 12, 2018 from https://www.sri.com/work/projects/special-education-elementarylongitudinal-study-seels 